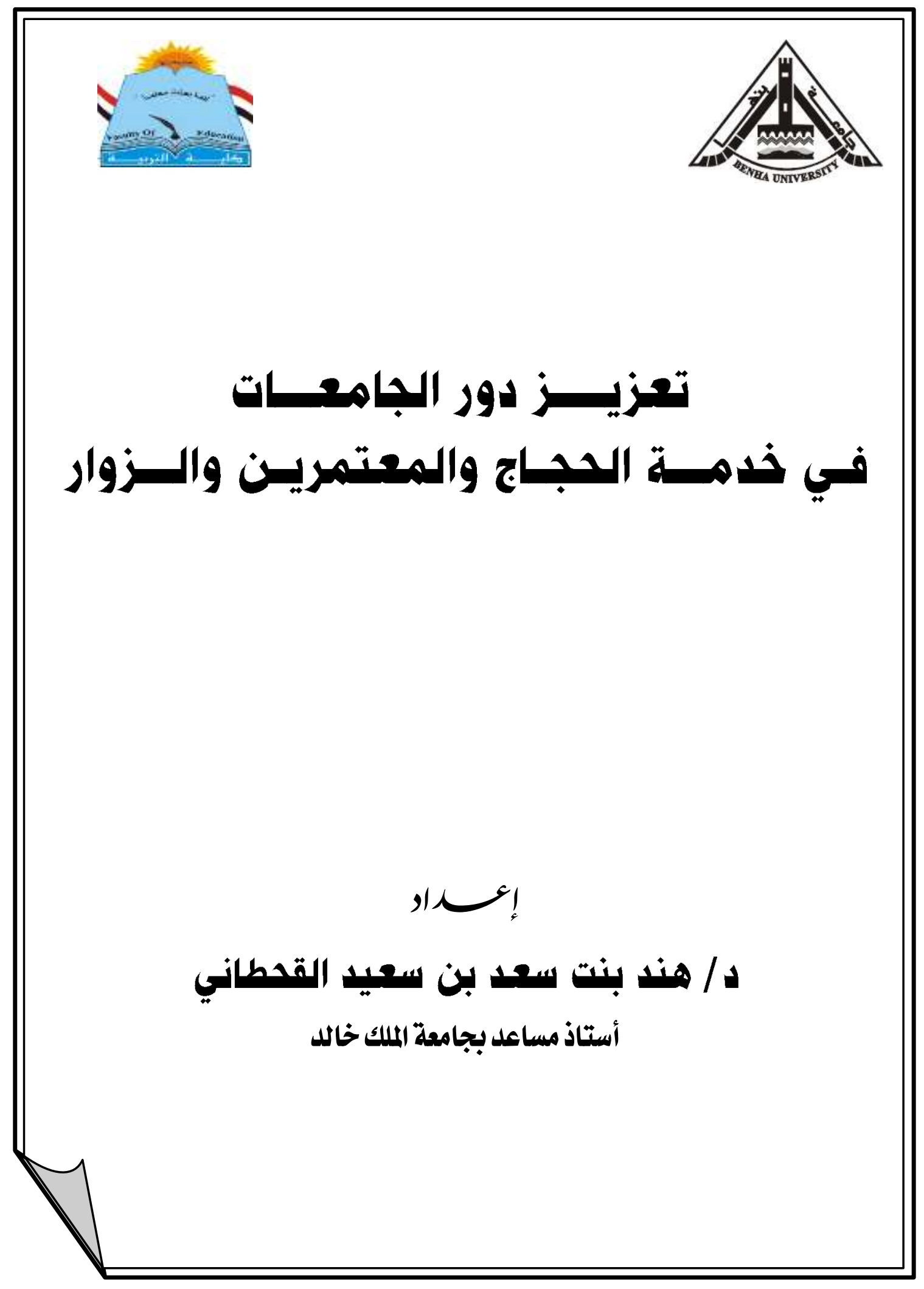




\title{
تعزيز دور الجامعات في خدمة الدجاج والمعتمرين والزوار
}

\author{
! إ
}

\section{/ هند بنت سعد بن سعيد القدطاني}

أستاذ مساعل بجامعة الملك خالد

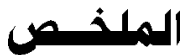

الحمد الله، والصـلاة والسـلام على رسول الله وعلى آله وصـبه أجمعين، ومـن اهتدى

$$
\text { بهداه إلى يوم الدين.. وبعد }
$$

لا يخفى على أحد الدور الذي تقدمسه جامعـات المملكة في خدمسة ضيوف الرحمن،

والمساهمة في نجاح موسم الحج كل عام. إلا أن لها دوراً أكبر من ذلك، فالجامعات السعودية ترتكز عليها نهضة البلاد وتقدمها. كما أكد على ذلك الأمير نايف بن عبد العزيز كحمه الله في كلمتهـ التي القاهـا في مؤتمر ( التقنيـة والاستـامة في العمـران) في جامعـة الملك سـود

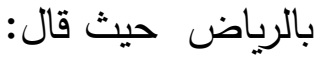

إن نجاح أي أمة من الأمم يعتمد في الأساس على إنسان هذه الأمة ونظرته لقيم العمل والعطاء، ولذلك نتطلع أن يتسابق الجميع لثقافة الإنتاج والإبداع، وأن تتغلب هذه الثقافة على ثقافة الاستهالك. والعالم اليوم تتسارع خطاه نحو ميادين المعرفة والإنجاز ، ولا مجال في هذا السـباق لمتكاسـل تجـاه قدرة نفسـه وحـق أمتـهـ ووطنـهـ.. ونأمـل مـن هذه الجامعـة والجامعـات السعودية الأخرى الارتقاء بالتعليم العالي والبحث العلمي في بلادنا إلى المستوى الذي يقودهم

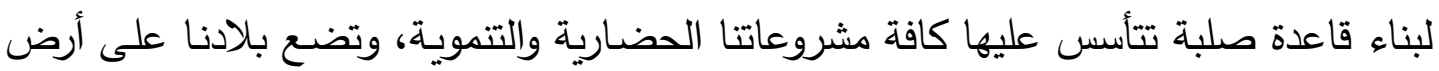

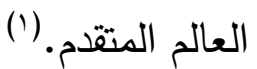

ويسعى البحث إلى بيـان الدور الكبير الذي تقوم بـه الجامعـات في المملكة العربيـة السعودية من مختلف المناطق لخدمة ضيوف الرحمن. في الحرمين الثريغين في مكة والمدينة، والمشاعر المقدسة.

( ) موقع جامعة الملك سعود، مقال بعنو ان: الأمير نايف: الجامعات السعودية مسؤولة عن بناء قاعدة تتأسس عليها كافة مشرو عتنا الحضارية و التنموية. http://news.ksu.edu.sa 
ويقصد البحث إلى بيان أبرز الأعمال التي تعزز دور الجامعات من مختلف المناطق

في خدمـة ضـيوف الرحمن. مـن خـلال مـا تقدمـه الجامعـة الإسـلامية عن طريق طلابهـا مـن

مختلف الجنسيات في العمل التطوعي لخدة الحجاج والمعتمرين والزوار • وما تقدمـه الجامعات من خلال مركز موهبة من دعم للأفكار المطروحة من طلاب وطالبات مركز موهبة، وتشجيع الابتكار في شتى المجالات والتي تخدم ضيوف الرحمن، في الحرمين الشريفين، والمشـاعر المقدسة. إضـافة إلى ما تقدمه الكليات الصحية بالجامعات المختلفة من دعم لخدمة ضيوف الرحمن القادمين من مختلف البلدان. لذا رأيت الكتابة في هذا الموضوع والذي اخترت لله عنوان:

\section{( تعزيز دور الجامعات في خدمة الدجاج والمعتمرين والزوار )}

وقد جعلته في مقدمة، وثلاثة مباحث، وخاتمه. المقدمة في أهمية الموضوع، وسبب اختياره

المبحـث الأول: دور طلاب الجامعة الإسلامية في خدمة ضيوف الرحمن المبحث الثاني: دور مركز موهبة في الجامعات لتشجيع الابتكار وطرح الأفكار لكل ما يخدم ضيوف الرحمن، وإيجاد البدائل المناسبة لما هو متاح حالياً للتمشي مع رؤيسة

$$
\text { r.r. }
$$

المبحث الثالث: دور كليات الجامعات الصحية ( الطب والعلوم التطبيقية ) في خدمة ضيوف الرحمن الخــاتمـــــة: وتشمل أهم النتائج والتوصيات 


\section{المبدث الأول}

\section{دور طلاب الجامعة الإسلامية في خدمة ضيوف الرحمن}

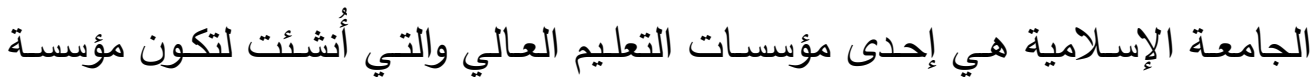
عالمية في غايتها تقوم على خدمة الإسلام، ونشر علومها ومعارفه وحفظ تراثه، وتبليخ رسالته الخالدة إلى العالم كله وتثقيف طلاب العلم المسلمين من شتى إنحاء العالم، وتكوين الفقهاء والعلمـاء المتخصصين في العلوم الإسـلامية والعربية، وإعداد البحوث والدراسـات العلميـة في مجالات العلوم الإسـلامية والعربيـة وسـائر العلوم وفروع المعرفـة الإنسانية التي يحتاج إليهـا المجتمع السعودي والمجتمع الإسلامي.

فاستقطبت الجامعة منذ إنشائها عام الربا اهـ إلى اليوم عشرات الآلاف من طلاب

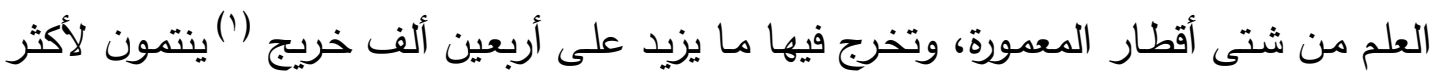
من مائة وثمانين دولة واقليماً. حصل منهم على درجة العالمية " الماجستير " ما يقارب من:

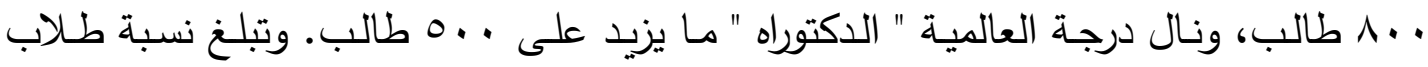

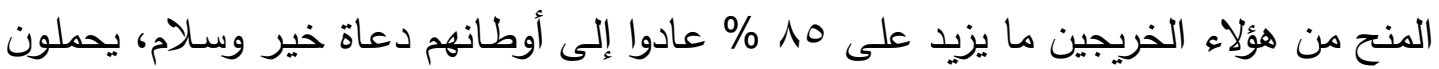

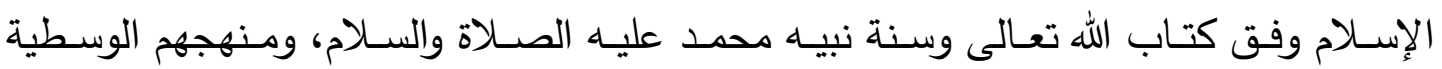

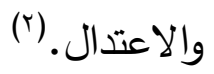

وتقوم الجامعة الإسلامية بالمدينة المنورة بخدمات جليلة ودور بارز في خدمة ضيوف الرحمن من حجاج ومعتمرين وزوار والتي تعكس من خلالها الأهداف التي تسعى عمادة شؤون بالئه الطلاب بالجامعة إلى تحقيقها ومن أبرزهاج(؟):

ت تنمية مهارات الطالب وقدرته على التخطيط والتطبيق، وتحمل المسؤولية. هتمية التقة بالنفس والتعويد على العمل الجماعي المبني على التعاون والإيثار .

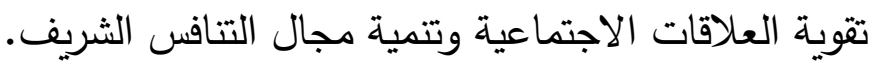
تعويد الطلاب على الجد وحسن استثمار الوقت وتنظيمه.

وغيرها من الأهداف التي تسعى العمادة إلى تحقيقها في ابنائها الطلاب من مختلف الجنسيات. 


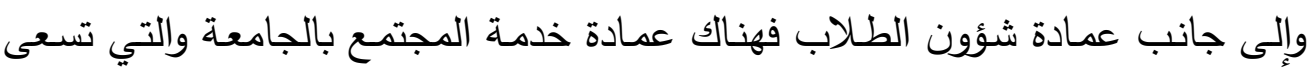

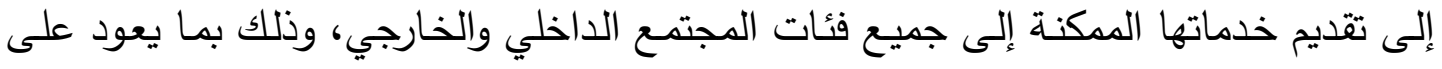
المجتمع بالنفع والفائدة الدينية والدنيوية.

ويشـارك طلاب الجامعة الإسـلامية بتعريف الحجاج بأمور الحسج والعمرة على الوجـهـ

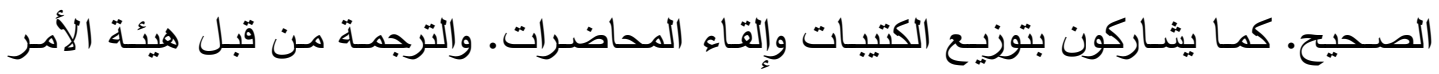

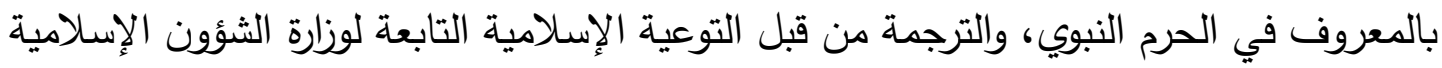

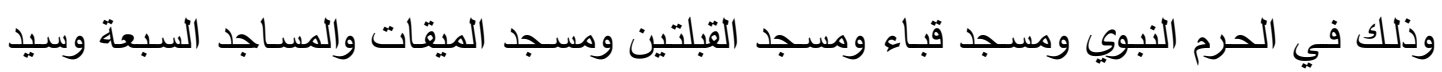
الثهاء إضافة للترجمة من قبل هيئة الأمر بالمعروف فرع المدينة في مقبرة البقيع ومقبرة سيد الثهداء والمساجد السبعة.

وتكـون أولويـة المشـاركة لطـلاب الدراســات العليـا "طـلاب الـدبلوم العـالي وطـلاب

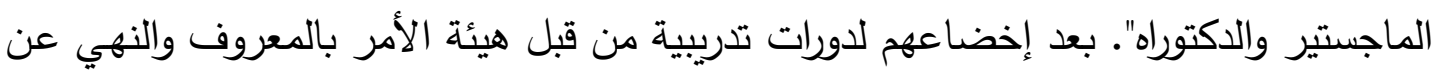

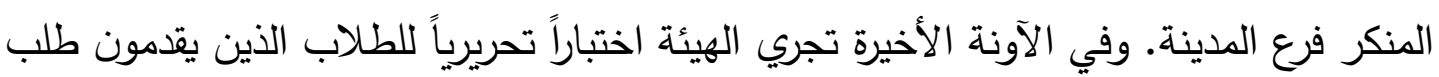
المشاركة أو تجرى لهم مقابلة شخصية. وأرى أن لطلاب الجامعة الإسلامية دوراً أكبر لابد من تعزيزه لخدمة ضيوف الرحمن،

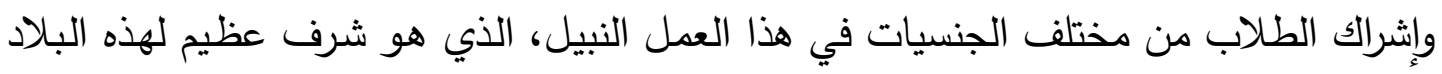

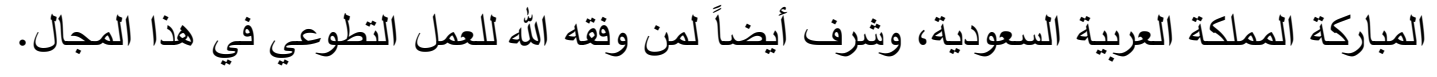
فإذا كانت عمادة خدمة المجتمع بالجامعة تسعى إلى تحقيق جملة من الأهداف من أبرزها والذي له علاقة بموضوعنا:

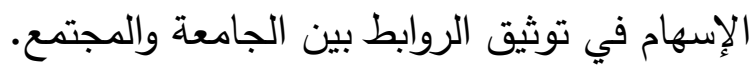
توسيع دائرة الاستفادة من الجامعة من خلال الإسهام في تأهيل الأفراد علمياً ومهنياً

$$
\text { بالتنسيق مع الجهات ذات العلاقة. }
$$

دعم برامج الدعوة إلى الله عز وجل، ونشر العلم الثرعي الصحيح الذي يحقق الأمن

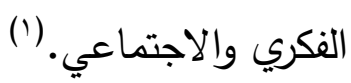

فإشراك طلبة الجامعة من الجنسيات المختلفة في خدمة ضيوف الرحمن يحقق الهدف الأول؛ وهو الإنهام في توثيق الروابط بين الجامعة والمجتمع. إضافة إلى الهدفين الآخرين. 
وعلى الجامعة تدريب هؤلاء الطلبة على العمل التطوعي في جميع ميادينه التي تتطلب مشاركتهم بها.

ومن ضمن الأعمال التي تبرز دور هؤلاء الطلاب في خدمة ضيوف الرحمن ما يلي:

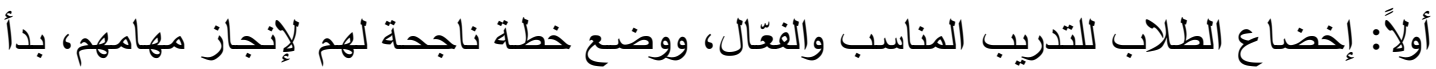

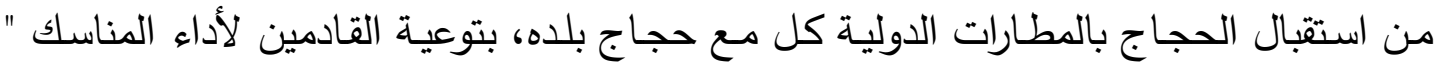

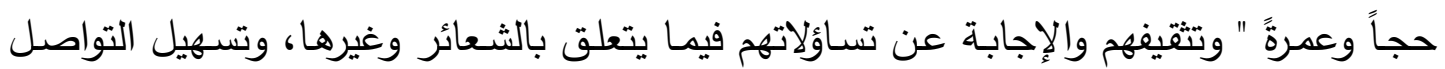

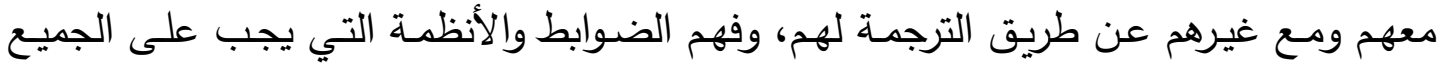

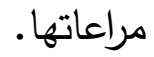
ثانياً: ينتقل المتطوعون مـع حمـلات الحج إلى مكة الدكرمة ويتوجهون للمسجد الحرام لأداء المناسك ، ويبقى المتطوعون معهم في المشاعر ؛ منى وعرفات ومزدلفة. لمساعدة من

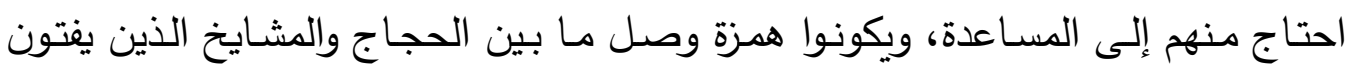
الناس ويجيبونهم عن اسئلتهم المتعلقة بالمناسك.

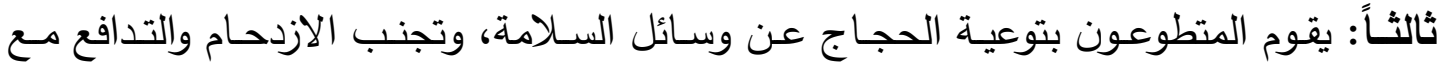

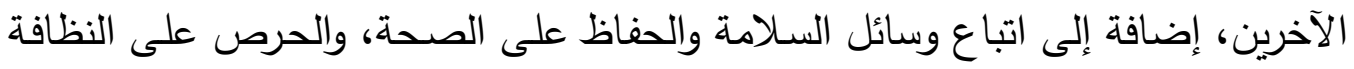

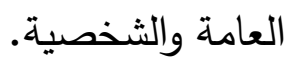

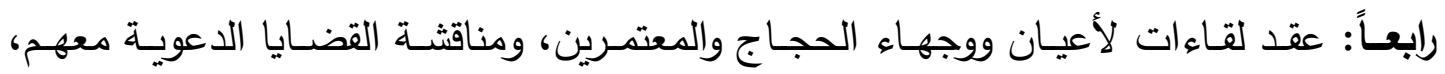
وترغيبهم في العمل للإسلام. (1) خامساً: مرافقة ضيوف الرحمن زوار المدينة المنورة للاطلاع على المواقع التاريخية والحضارية والأثرية التي تضمها طيبة الطيبة وتقديم شرح مفصل عن تلك المواقع التاريخية وارتباطها

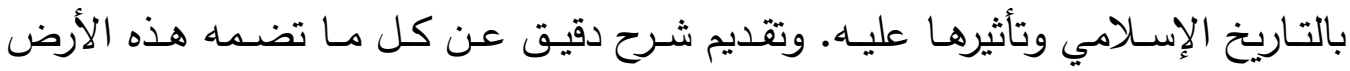
الطاهرة وما تقدمه حكومة خادم الحرمين الثريفين -حفظه الله- في خدمتهم وفي خدمة

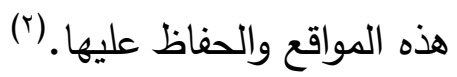




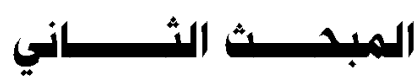

دور مركز موهبة في الجامعات لتشجيع الابتكاروطرح الأفكار لكل ما يخلده ضيوف الرحمن،

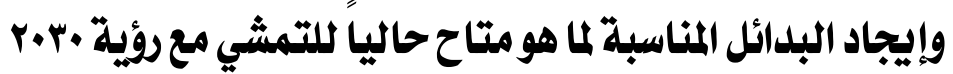

انطلاقا من حرص حكومـة خادم الحرمين الشريفين - حفظه الله- وولي عهده الأمين

وولي ولي عهده للنهوض بهذه البلاد جاءت رؤيـة . . . والتي أشـاد فيها ولي ولي العهد الأمير محمد بن سلمان -وفقه الله- بالشباب حيث قال:

في وطننا وفرة من بدائل الطاقة المتجددة، وفيها ثروات سخية من الذهب والفوسفات واليورانيوم وغيرها، وأهم من هذا كله، ثروتنا الأولى التي لا تعادلها ثروة مهما بلغت: شعب

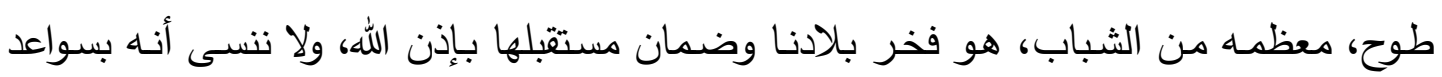
أبنائها قامت هذه الدولة في ظروف بالغة الصعوبة، عندما وحدها الملك عبد العزيز بن عبد الرحمن آل سعود- طيب الله ثراه- وبسواعد أبنائه، سيفاجئ هذا الوطن العالم من جديد. (') كما تهتم خطط التتمية في المملكة العربية السعودية بتطوير العنصر البشري كأسـاس للنهوض بالمجتمع في شتى المجالات الاجتماعية والاقتصادية والقدرة على المنافسة العالمية، وفي سبيل تحقيق هذه الغاية تقدم الدولة كل الرعاية للتعليم بجميع مراحله، كما تشجع العلم والعلماء، وتعنى برعاية المتميزين والموهبين والمبدعين من كافة المراحل. وتعتبر البرامج التي تقدمها مؤسسة الملك عبد العزيز ورجاله للموهبة والإبداع خير مثال لذلك. وحيث تسعى الجامعات السعودية أن تكون منارات إقليمية وعالمية للعلم والمعرفة والتميز ، فقد ظهرت الحاجـة إلى إنشاء مراكز لرعاية الموهبة والإبداع والتميز داخل الجامعات، بحيث تقوم باكتشاف الطلاب والطالبات الموهوبين والمتميزين والمبدعين في شتى المجالات الثقافية والفنيـة، كما تقوم بتقديم البرامج الإثرائية المناسبة لكل فئة منهم للوصول إلى تطوير قدراتهح

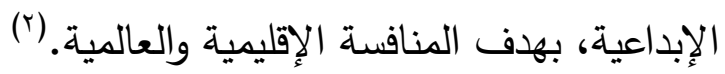
وبالفعل قامت الجامعات في مختلف المناطق بإنشاء مراكز للموهبة والإبداع تدعم من خلالها الطلاب والطالبات الموهوبين والمبدعين والمتميزين في شتى المجالات. 


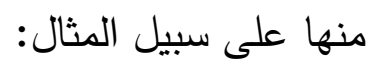

" المركز الوطني لأبحاث الموهبة والإبداع بجامعة الملك فيصل بالأحساء.

مركز الموهبة والإبداع بجامعة الملك عبد العزيز بجدة.

مركز الموهبة والإبداع والتميز بجامعة طيبة بالمدينة المنورة.

مركز الموهبة والإبداع بجامعة الملك خالد بأبها.

وقد حرصت الجامعات على تثجيع أبنائها الموهوبين من الطلاب والطالبات البات ودعمهر

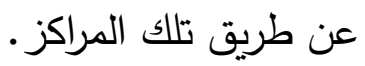

وهنا يأتي دور مركز موهبة في الجامعات لتشجيع الابتكار وطرح الأفكار لكل ما يخدم ضيوف الرحمن من حجاج ومعتمرين وزوار • ويتضح هذا الدور فيما يلي:

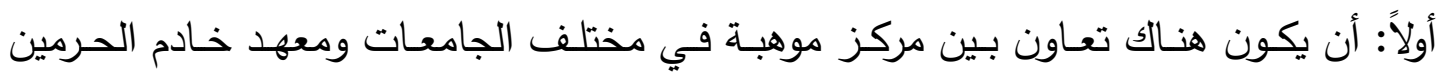

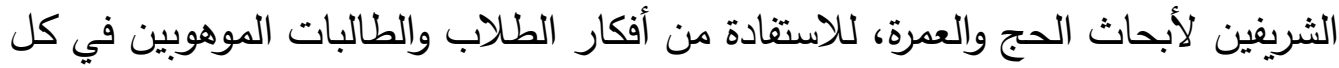

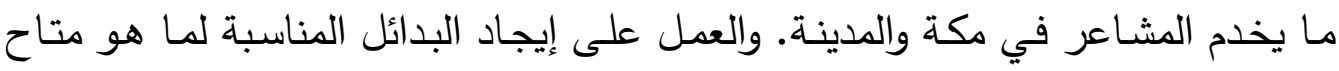

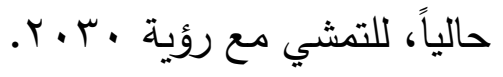

ثانياً: طرح أبرز المشاكل التي تقع في المشاعر أثثاء تأدية المناسك "الحج والعمرة والزيـارة" وبحث سبل حلها عن طريق ما يطرحه طلاب موهبة من ابتكارات ومشاريع يمكن تتفيذها

$$
\text { على أرض الواقع. }
$$

ثالثاً: عقد مسابقات تنافسية بين الطلاب في البحث عن أفضل الوسائل وأيسرها لخدمة ضيوف

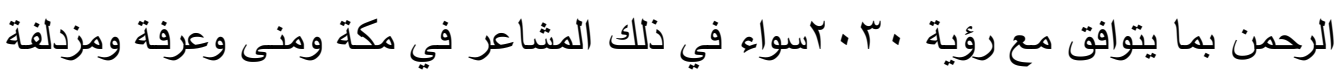

$$
\text { أوفي الحرمين الشريفين. }
$$

ولا شك أننا سنجد من أبنائنا وبناتتا في مركز موهبة الكثير من الأفكار والبدائل التي تخدم ضيوف الرحمن من حجاج ومعتمرين وزوار، وتعد بمستقبل أفضل وأجمل بمشيئة الله. 


\section{المبــث الث}

\section{دوركليات الجامعات الصحية ( الطب والعلوم التطبيقية ) في خلمة ضيوف الرحمن}

إيمانـا من الجامعات بدورها المنـاط بها في المجتمع لخدمـة ضيوف الرحمن؛ تسعى بالتعاون مع جمعية الهلال الأحمر السعودي لتقديم كافة الخدمات والمساعدات الطبية للحجاج والمعتمرين والزوار • ويشـارك المتطوعون من الكليات الصـحية (الطب والعلوم التطبيقيـة) مـن مختلف الجامعات رجالاً ونساءً في العمل التطوعي في موسم الحج والعمرة والزيـارة. ويقدمون

لضيوف الرحمن المساعدات الطبية والاسعافات الأولية التي يحتاجون إليها. وللجامعات دوراً أكبر في هذا المجال يمكن إيجازه فيما يلي:

أولاً: التتسيق فيما بين الجامعات للمشاركة بالعمل التطوعي لخدمة ضيوف الرحمن كل عام بما يحقق المشاركة الفعالة والأهداف المرجوة. في موسم الحج والعمرة والزيارة. ثانيـاً: تشجيع البحث العلمي، وإجراء المزيــ من الأبحاث في المختبرات العلميـة للعـلاج من فوهن الأمـراض المعديـة والتي قد تتنقل مـع الحجـاج الوافدين من مختلف المنـاطق والبيئات. والعمل على تطوير اللقاحات للتصدي لهذه الأمراض والوقاية منها. ثالثاً: تدريب المتطوعين على كيفية التعامل مع الحالات الطارئة في المشاعر المقدسة، وسرعة علاج الأمراض المزمنة التي قد يعاني منها بعض الحجاج كالسكري والضغط وأمراض الجهاز التنفسي وغيرها. أو ضربات الشمس، وكيفية الوقاية منها. رابعاً: الاستفادة من خبرات الأطباء الذين لهم مشاركة في الأعوام السابقة في العمل التطوعي لخدمة ضيوف الرحمن من حجاج ومعتمرين وزوار . خامساً: العمل على تذليل الصعوبات والمعوقات التي قد تواجه المتطوعين من طلاب وطالبات في الكليات الصحية المختلفة للقيام بمهامهم على أكمل وجه. وإن ما قدمته الجامعات من خلال مشاركتها في خدمة ضيوف الرحمن خلال الأعوام السابقة لهو فخر لكل مسلم ومسلمة يعيشون في هذا الوطن الغالي. وأذكر بعضاً من مشاركات الجامعات في هذا المجال: فقد شارك جr ط طالباً من جامعة الدمام هذا العام ضمن الطواقم الطبية التي تواجدت في الحج لتقديم الخدمات الصحية تحت مظلة الهلال الأحمر السعودي ضمن فريق التطوع المكون من · . م متطوع ومتطوعة من جميع أنحاء مملكتتا الغالية في مختلف التخصصات ..حيث 
قدم الطلاب كافة الخدمات والمسـاعدات الطبيـة للحجاج وقد حظي المتطوعون بثقة الهلال الأحمر السعودي نظير ما يمتلكون من التأهيل والرغبة الجادة في خدمة ضيوف الرحمن. (') كما دشّن وكيل جامعة شقراء العيادة الطبية المتنقلة والمنفذة من الجامعة في هـ ذئي الحجة VT؟ اهـ للمشاركة في مركز خدمة ضيوف الرحمن وقاصدي المشاعر المقدسة والتي شملت فعاليات وبرامج متتوعة جاءت مبادرة للعام الرابع على التوالي في سبيل توفير خدمة طبية وعلاجية للحجاج.. وتضم جملة من خدمات طبية وعلاجية للحالات المرضية وخدمات

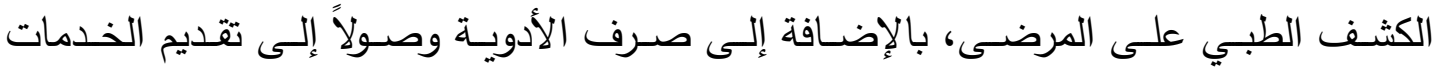

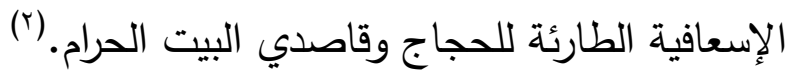

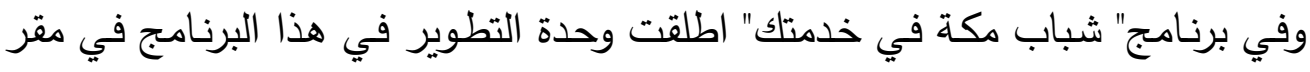

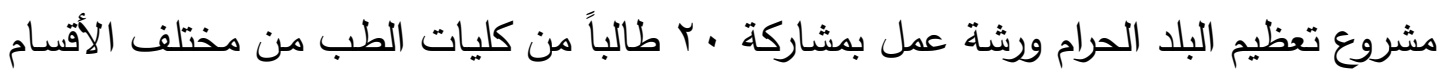

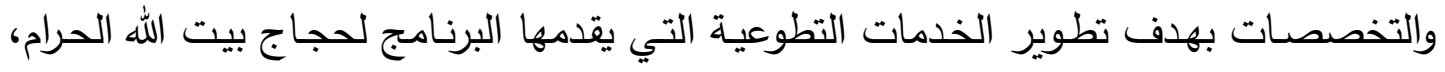

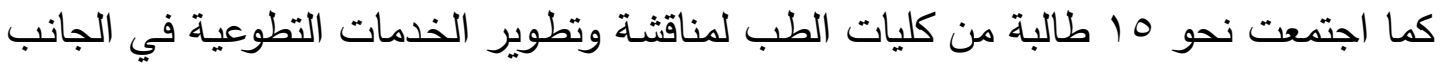
النسائي. ويشار إلى أن برنامج "شباب مكة في خدمتك" يطلق نشاطاً سنوياً في موسم الحج

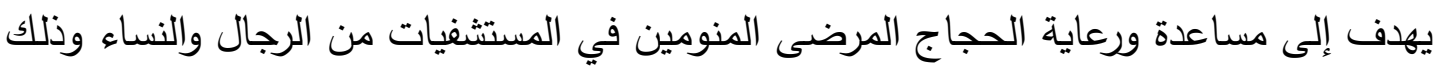

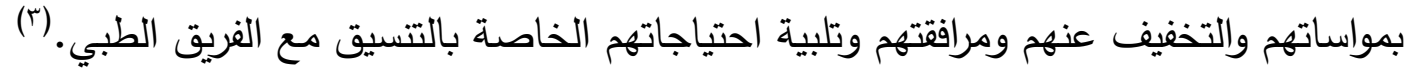




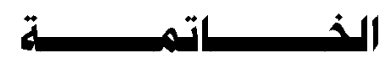

تتلخص أهم نتائج البحث فيما يلي:

تقوم الجامعات في المملكة العربية السعودية في مختلف المناطق بدور هام وكبير في خدمة لهات

$$
\text { ضيوف الرحمن، من حجاج ومعتمرين وزوار . }
$$

يقوم طلاب الجامعة الإسلامية بالمدينة المنورة من مختلف الجنسيات بدور كبير في خدمة فئة

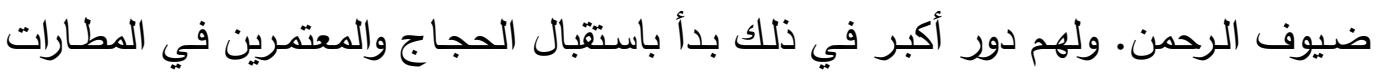
الدولية لتوعية القادمين وتثقيفهم ، وتسهيل التواصل معهم عن طريق الترجمة لهم وفهم

$$
\text { الضوابط والأنظمة التي يجب على الجميع مراعاتها. }
$$

تشجيع الطلاب والطالبات في مركز موهبة على الإبتكار وطرح الأفكار لكل ما من شأنه ملاعه

$$
\text { خدمة ضيوف الرحمن. }
$$

- العمل على التعاون بين مركز موهبة في مختلف الجامعات ومعهد خادم الحرمين الثريفين

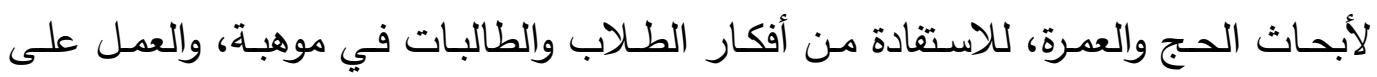

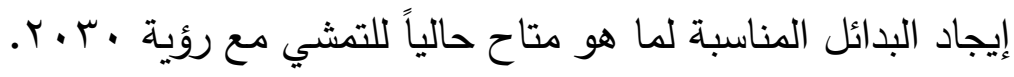

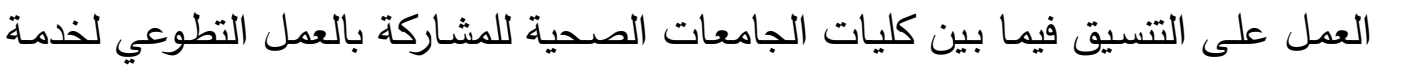
ضيوف الرحمن كل عام، بما يحقق المشاركة الفعّالة والأهداف المرجوة.

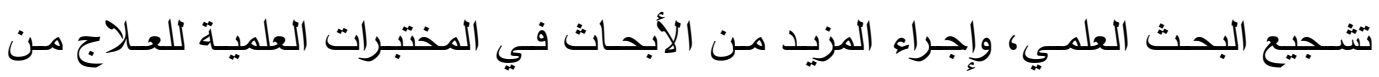

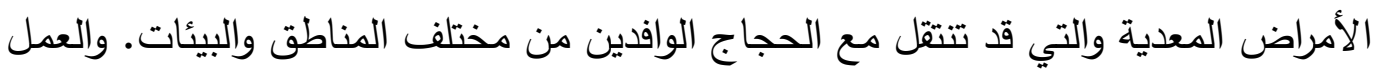
على تطوير اللقاحات للتصدي لهذه الأمراض والوقاية منها.

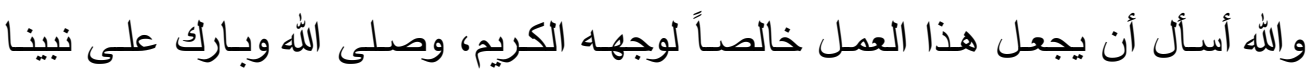
محمد وعلى آله وصحبه أجمعين، والحمد لله رب العالمين. 


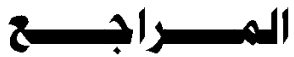

موقع جامعة الملك سعود، مقال بعنوان: الأمير نايف: الجامعات السعودية مسؤولة عن بناء قاعدة تتأسس عليها كافة مشروعتنا الحضارية والتتموية. http://news.ksu.edu.sa

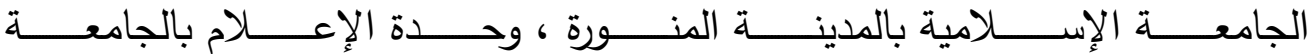

http://www.iu.edu.saه) Irr

http://www.iu.edu.sa $\quad$ الجامعة الإسلامية ، عمادة شؤون الطلاب

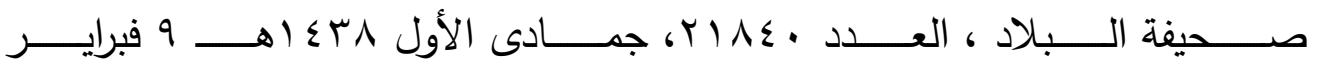
WWw.albiladdaily.compr $\mathrm{IV}$

http://www.iu.edu.sa الجامعة الإسلامية ، عمادة خدمة المجتمع

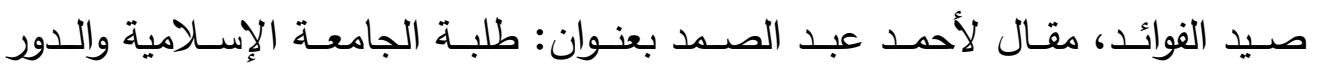
https://saaid.net/aldawah/320.htm المنتظر

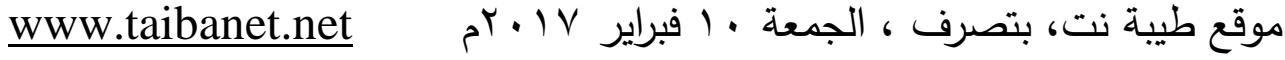

https://www.taibaha.edu.sa جامعة طيبة، مركز الموهبة والإبداع والتميز

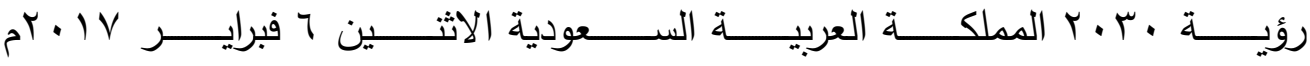
http://vision2030.gov.sa

http://www.uod.edu.sa موقع جامعة الإمام عبد الرحمن بن فيصل بالدمام

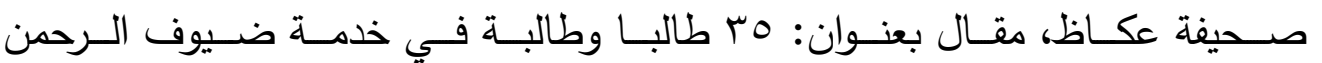
http://okaz.com.sa http://ien.sa صحيفة عين الاكترونية 